\title{
The structure and properties of a carbon nanotube $(7,7)$ with a vacancy defect
}

\author{
S. A. Sozykin ${ }^{\dagger}$, V.P. Beskachko \\ †sozykinsa@susu.ru \\ South Ural State University, Chelyabinsk, 454084, Russia
}

\begin{abstract}
Carbon nanotubes (CNTs) still draw great attention of researchers due to their possible use as anodes for lithium-ion batteries. The capacity of the anode for lithium ions is defined by the efficiency of diffusion of these ions to the adsorption centers located on the outer or inner surface of the nanotubes, as well as between the layers of multi-walled nanotubes. The inner surface can be accessed through the open ends of the tubes or defects in their frame. Moreover, the defects create more efficient adsorption sites than the surface of a perfect tube. This work presents the results of the ab-initio modeling of the lithium adsorption on a carbon nanotube $(7,7)$ with a vacancy-type defect. The simulation was carried out using density functional theory implemented in the SIESTA package. The Ceperley-Alder exchange-correlation functional and the DZP basis set were used. The formation energies of vacancy defects of two types were determined. Additionally, for each vacancy type, the binding energies of lithium atoms adsorbed inside and outside the CNT $(7,7)$ near the defect were calculated. These binding energies were shown to be up to twice bigger than on a perfect CNT. The enhancing effect of the vacancy on the CNT sorption activity was found to be wide-ranged: it was observed for adsorption sites in the first and second surroundings of the defect and even for sites located on the tube surface opposite to the defect.
\end{abstract}

Keywords: carbon nanotubes, modeling, vacancy, lithium, adsorption.

\section{Строение и свойства углеродной нанотрубки $(7,7)$ с дефектом вакансии}

\author{
Созыкин С. А. ${ }^{\dagger}$, Бескачко В.П. \\ Южно-Уральский государственный университет, Челябинск, 454084, Россия
}

Интерес к углеродным нанотрубкам не угасает с годами отчасти из-за перспектив их использования в качестве анодов литий-ионных батарей. Ёмкость анода по ионам лития является результатом эффективной диффузии этих ионов к центрам адсорбции, расположенным на внешней или внутренней поверхности нанотрубок, а также между слоями многослойных нанотрубок. Доступ к внутренним поверхностям возможен через открытые торцы трубок или дефекты в их каркасе. Присутствие дефектов, кроме того, способно создать более эффективные центры адсорбции по сравнению с поверхностью совершенной трубки. В работе представлены результаты неэмпирического моделирования адсорбции лития на углеродной нанотрубке $(7,7)$, содержащей дефект типа вакансии. Моделирование проводилось с помощью программы SIESTA (Spanish Initiative for Electronic Simulations with Thousands of Atoms). Использовался обменно-корреляционный функционал Каперлея-Алдера (приближение локальной плотности) и базисный набор DZP (double zeta quality plus polarization functions). В рамках теории функционала электронной плотности определены энергии образования двух вариантов реализации дефекта вакансии, для каждой реализации рассчитаны энергии адсорбции лития на центрах, расположенных на внешней и внутренней поверхностях нанотрубки. Показано, что энергия адсорбции на центрах в области дефектов до двух раз превосходит таковую на центрах совершенной трубки. Более того, эффект повышения сорбционной активности имеет дальнодействующий характер - обнаруживается для центров адсорбции в первом и втором окружении дефекта и даже для центров, расположенных на трубке противоположно дефекту.

Ключевые слова: углеродные нанотрубки, моделирование, вакансия, литий, адсорбция. 


\section{Introduction}

The growing interest in carbon nanostructures is caused in part by the need to solve a number of problems in the fields of ecology and energy: the creation of mobile environmentally friendly energy sources for use in transport and in communication systems, the accumulation and storage of energy from renewable irregular sources, such as sun and wind. Lithium-ion batteries (Nobel Prize in Chemistry 2019) have received the greatest recognition as mobile sources of electrical energy due to their high specific energy, long service life (up to 2000 chargedischarge cycles), and high voltage (almost double that of lead-acid batteries). Although lithium ions are one of the most effective charge carriers in batteries, the service characteristics of such batteries significantly depend on the choice of other elements of its design: the anode, cathode and electrolyte materials. Here, the choice is less clear, and active theoretical and experimental research is underway to identify the most promising materials. Materials based on carbon in its low-dimensional forms are of great interest, and the use of carbon nanotubes (CNTs) as anodes in lithiumion batteries is promising [1-3]. The capacity of the anode for lithium ions is the result of the effective diffusion of these ions to the adsorption centers located on the outer or inner surface of the nanotubes, as well as between the layers of multilayer CNTs. Access to the inner surface is possible through the open ends of the tubes or defects in their frame. The presence of defects can create more efficient adsorption centers compared to the surface of a perfect tube. Theoretical calculations show that reversible capacities, exceeding the stoichiometry of $\mathrm{LiC} 2(>1116 \mathrm{mAh} / \mathrm{g})$, are achievable for materials based on single-walled CNTs, which significantly exceed this indicator for graphite $[4,5]$. The study by Noh et al. [6] on electrode materials based on CNTs is of great interest. They examined the effect of the preliminary chemical and mechanical processing of CNTs on battery performance. They found that the chemical modification of the tubes increases the lithium capacity of the battery, but also leads to rapid degradation during charging and discharging, and to failure. Mechanical processing does not have such consequences, but significantly improves the behavior of CNTs during charging due to the appearance of a large number of defects in the CNT structure. The effect of a double vacancy defect on the adsorption of lithium by CNTs has been considered [7]. This work studies the effect of a single vacancy defect on the structural and sorption properties of CNTs with metallic conductivity.

\section{Defective CNT Models}

The presence of structural defects in CNTs leads to deformations that propagate far from the location of the defect. To simulate isolated defects (which do not interact with one another), it is necessary to consider sufficiently long fragments of nanotubes [8]. In the present study, a CNT fragment of type $(m, m)$ (armchair) at $m=7$ was examined. It contains 8 unit cells $4 \cdot m=28$ and atoms per cell, is approximately $2 \mathrm{~nm}$ long, and has a diameter of about $1 \mathrm{~nm}$.
The total number of carbon atoms in the defect-free model is 224 . The integer number of cells in the model allows the use of periodic boundary conditions. The computational cell (supercell) was a parallelepiped with dimensions $a \times b \times c=10 \times 10 \times 1.9545 \mathrm{~nm}$. The tube was placed along a short edge of the parallelepiped, the size of which was determined in preliminary numerical experiments considering the minimum total energy of the system. The two remaining dimensions were chosen such that their size excluded the interaction of the model with its images in neighboring supercells.

In armchair nanotubes, there are two nonequivalent positions for carbon atoms and, accordingly, two types of single vacancies, designated as $a$-circ and $a$-tilt (see Fig. 1).

\section{Modeling method}

The simulation was carried out using density functional theory implemented in the SIESTA package [9] (atom-like basis). The geometry of the system was optimized using the conjugate gradient method. The criterion of convergence in terms of the maximum force acting on an atom was taken as the standard (default) $0.04 \mathrm{eV} / \AA$ (parameter ZM. ForceTolLength). Atomic displacements during geometry optimization did not exceed $0.377 \AA$ (parameter ZM. MaxDispLength). The Caperley-Alder exchange correlation functional (local density approximation) and the DZP basis set were used. The optimal parameters for generating the basis set were taken from [10]. A [1,1,32] MonkhorstPack set of k-points and a mesh cut-off of 200 Ry were used for calculations. The analysis of the calculation results of the SIESTA package and the preparation of images of the atomic structure were carried out in GUI4dft program [11], using the supercomputer resources of South Ural State University [12].

\section{Results and discussion}

\subsection{The energies of adsorption of lithium on defect-free CNTs}

The adsorption energy $\Delta E_{\text {ads }}$ was calculated by: $\Delta E_{\text {ads }}=E_{(7,7)+\mathrm{Li}}-$ $-\left(E_{(7,7)}+E_{\mathrm{Li}}+E_{\mathrm{CP}}\right)$, where $E_{(7,7)+\mathrm{Li}}, E_{(7,7)}$ and $E_{\mathrm{Li}}$ are the total energy of the "nanotube + adsorbed $\mathrm{Li}$ atom" system, the total energy of an individual nanotube, and the energy of an isolated lithium atom, respectively. The value $E_{\mathrm{CP}}$ is a Boys and Bernardi counterpoise correction [13], which may be significant even for optimized atom-like basis sets [14]. The energy of $\Delta E_{\text {ads }}$ without consideration of $E_{\mathrm{CP}}$ was calculated in a previous paper [7] for the same tube, using the same methods and $-1.80 \mathrm{eV}$ and $-2.17 \mathrm{eV}$ for adsorption on the outer and inner surfaces of the tube, respectively. The difference of these energies, $\Delta E_{\text {ads }}^{\text {(out-in) }}$ was $0.37 \mathrm{eV}$. Taking into account the Boys and Bernardi correction, these energies were equal to $-1.66 \mathrm{eV}$ and $-1.81 \mathrm{eV}$, respectively. The correction increased $\Delta E_{\text {ads }}^{\text {out }}$ by $0.14 \mathrm{eV}$, and $\Delta E_{\text {ads }}^{\text {in }}$ by $0.36 \mathrm{eV}$. The difference between the energies of external and internal adsorption was reduced to $\Delta E_{\text {ads }}^{\text {(out-in) }}=0.15 \mathrm{eV}$. This means that the correction of $E_{\mathrm{CP}}$ depends on the sign of the surface 


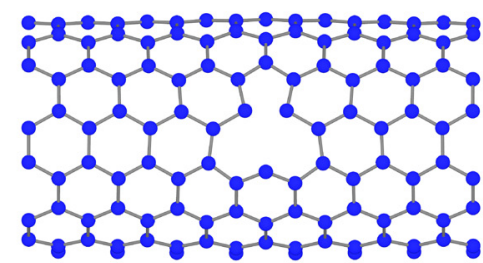

a
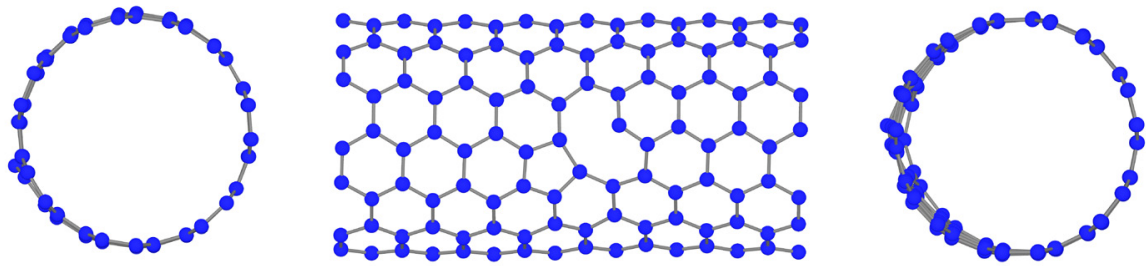

b

Fig. 1. The atomic structure of a carbon nanotube $(7,7)$ with vacancy defects $a$-circ (a), a-tilt (b).

curvature and is more important in calculating the energy of internal adsorption than external. When VASP was used to study the adsorption of lithium, the adsorption energies for CNT $(6,6)$ were approximately the same [15].

In the model considered here, a CNT fragment of 8 unit cells with periodic boundary conditions, is possibly redundant for determining the $\Delta E_{\text {ads }}$ of a single lithium atom on a perfect tube. For this, half the model is also suitable [10]. This makes it difficult to directly compare the results with data from the literature, as do a number of factors affecting the calculations which change from study to study: the calculation method, the calculation scheme and its parameters, boundary conditions, model parameters, etc. However, when dealing with the issues of lithium adsorption, it is useful to keep in mind the following results of $a b$ initio calculations.

For the simplest system of the type under consideration (benzene ring $+\mathrm{Li}$ atom), calculations of the adsorption energy of $\mathrm{Li}$ [16] (using a wide basis set) resulted in $-1.67 \mathrm{eV}$. In that article, there is no mention of taking into account the superposition error of the basis set, although the basis of atom-like orbitals was used. Note that when using a more modest basis, this value was $-1.84 \mathrm{eV}$. For the CNT $(5,5)$ considered in the same place, the values of $\Delta E_{\text {ads }}$ on the outer and inner surfaces of the tube were -2.17 and $-2.33 \mathrm{eV}$, respectively, so that $\Delta E_{\text {ads }}^{\text {(out-in) }}=0.16 \mathrm{eV}$.

In the next approximation of the geometry of CNT $(7,7)$, the "flat" analogue of CNT, graphene, is considered. Yang et al. [17] performed calculations on the plane wave basis (in the VASP package). The adsorption energy for the lowest of the considered concentrations of $\mathrm{Li}(1 / 32 \approx$ at.\%) adsorbed on graphene, at which it can be assumed that $\mathrm{Li}$ atoms already interact weakly with each other, was $\Delta E_{\mathrm{ads}}=-1.12 \mathrm{eV}$.

The energies of lithium adsorption on $\operatorname{CNT}(5,5)$, which is a thinner tube than $(7,7)$, with a diameter of $0.68 \mathrm{~nm}$ are provided in $[18,19]$. According to Koh et al. [19] the energy of lithium adsorption on CNT $(5,5)$ of 80 carbon atoms is $-1.72 \mathrm{eV}$. Most likely, this value refers to external adsorption, although there are no explicit indications of this in the paper. Khantha et al. [18] obtained the adsorption energy for the CNT model $(5,5)$ of 60 carbon atoms: $-2.05 \mathrm{eV}$ on the outer surface and $-2.11 \mathrm{eV}$ on the inner surface. Song et al. [20] found the internal adsorption energy is $-2 \mathrm{eV}$ for CNT $(10,0)$ with a diameter of $0.78 \mathrm{~nm}$, far from the ends of the model, using the molecular cluster model. Finally, Liu et al. [21] studied the dependence of the energies of internal and external adsorption of Li on the diameter of a CNT of the type $(n, n)$ for $n=3,4,5,6$, also using the molecular cluster model. They showed that in this sequence, $\Delta E_{\text {ads }}^{\text {in }}$ increases rapidly and $\Delta E_{\text {ads }}^{\text {out }}$ decreases relatively slowly, so that for $n=6$ they become equal, and it can be assumed that $\Delta E_{\text {ads }}^{\text {in }}=\Delta E_{\text {ads }}^{\text {out }} \approx 0.8 \mathrm{eV}$ and that the adsorption energy of lithium ceases to depend on the tube diameter or on the sign of the surface curvature for tubes with a diameter larger than $n=6$, and further that it becomes equal to the adsorption energy of lithium on graphene. There is no doubt about the correctness of this pattern, but there are doubts about the reliability of determining the "critical" value of $n$, at which the curvature of the surface becomes insignificant. In particular, the results obtained in this work show that the value $n=7$ of is not yet critical, even with the Boys and Bernardi corrections. The discrepancy seems to be the result of using a model of a molecular cluster in which there are always size effects due to the presence of tube edges and related deformations of the carbon cage. This factor, however, is not discussed in Liu et al. [21].

It can be concluded that the chosen model and research method make it possible to obtain adsorption energies consistent with the data from the literature concerning systems similar to those considered in this work.

\subsection{Energy of vacancy formation}

The vacancy defect formation energy was estimated by: $E_{\text {vac }}=E_{\text {def }}-E_{(7,7)}+\mu_{\mathrm{C}}$ where $E_{\text {def }}$ is the defect nanotube energy, $E_{(7,7)}$ is the defect-free nanotube energy, and $\mu_{C}$ is the chemical potential of carbon (the ratio of the total energy of a perfect nanotube to the number of atoms).

The energies of vacancy formation in the a-circ and a-tilt configurations were 7.23 and $6.18 \mathrm{eV}$, respectively, so that the a-tilt configuration was energetically more favorable than the competing a-circ configuration by $1.05 \mathrm{eV}$. Similar results were obtained by Kroes et al. [22] for a $(10,0)$ zigzag tube with a diameter of $0.78 \mathrm{~nm}$. Here, the difference in the formation energies of a pair of similar defects is $1.1-1.5 \mathrm{eV}$, depending on the type of exchange correlation functional used. The formation energies of single vacancies themselves are $5.5-7.1 \mathrm{eV}$, depending on the type of vacancy and the exchange correlation functional. According to Padilha et al. [23] the formation energy of a vacancy in a nanotube $(7,7)$ is approximately $4.5 \mathrm{eV}$ (in the GGA approximation for the exchange-correlation interaction). The data we obtained are comparable with the data from the literature.

\subsection{Lithium adsorption centers on $\operatorname{CNT}(7,7)$ near the vacancy defect}

The defect itself is a 9-membered ring of carbon atoms (9-ring), bordered by seven 6-rings (hexagons) and one 5-ring. In the 9-ring, one of the atoms is two-coordinated 
(has one dangling bond). Such a defect is classified as $5-1 \mathrm{db}$ (a 5-ring and 1 dangling bond) [24].

To assess the effect of a vacancy defect on the adsorption of lithium, the defect itself and its first two environments are considered. The center on the opposite, defect-free, side of the nanotube is also considered as a potential adsorption center for comparison. Fig. 2 shows a scan of the surface of a nanotube $(7,7)$. It was obtained by projecting all the atoms (including carbon atoms near the defect and a lithium atom) onto a cylindrical surface, the diameter of which is equal to the diameter of a defect-free nanotube $(0.95 \mathrm{~nm})$. The symbols indicated in the legend show the equilibrium positions of $\mathrm{Li}$ atoms during internal and external adsorption. The position 0 denotes a 6-ring located in a position diametrically opposite the defect. Obviously, of all the rings in the vicinity of the cross section of the tube passing through the defect, this ring will be least affected by its influence. Positions 1 and 2 designate the centers of the 9-ring (defect) and the adjacent 5-ring, respectively. Positions 3-7 mark the possible adsorption centers in the form of 6-rings in the first environment of the defect (marked by hatching). Positions 8-15 denote the adsorption centers from the second environment, which occupy nonequivalent positions with respect to the defect.

With a defect-free nanotube, lithium atoms are adsorbed over the centers of the 6-rings at a distance of about $0.2 \mathrm{~nm}$ to the nearest carbon atoms. Each of the starting positions of the adsorption centers for defective nanotubes was chosen for similar considerations: a single lithium atom was located above the center of one of the rings marked in Fig. 2. Taking into account two realizations of the defect ( $a$-circ and $a$-tilt), as well as adsorption in the cavity and on the outer surface of the nanotube, $4 \cdot 16=64$ starting configurations were obtained.

In minimizing the energy of the system, some of the lithium atoms were displaced from their starting positions to the center of the defect. Such positions correspond to unstable adsorption centers. As Fig. 2 shows, with external adsorption, there are a greater number of stable adsorption centers than with internal adsorption. For internal adsorption in the vicinity of the a-tilt defect, two out of five centers (the $3^{\text {rd }}$ and $\left.7^{\text {th }}\right)$ are unstable, and in the vicinity of the a-circ defect all centers are unstable except for the $4^{\text {th }}$. In the second

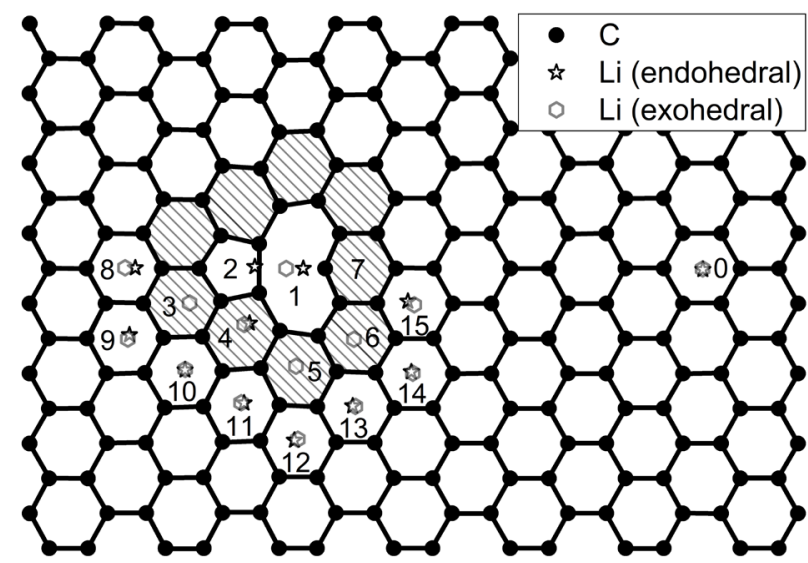

environment, all lithium adsorption centers are stable on both sides of the tube surface.

The minimum total energies of the system in all four cases (two types of defect, internal and external adsorption) corresponded to the center of the defect (position 1). Fig. 3 shows the excess adsorption energies $\left(\Delta E_{\text {ads }}^{(i, 1)}\right)$ for stable centers, that is, the adsorption energies calculated in relation to the adsorption energy on the center 1: $\Delta E_{\text {ads }}^{(i, 1)}=\Delta E_{\text {ads }}^{i}-\Delta E_{\text {ads }}^{1}$ $i=0,2,3, \ldots, 15$. Note that the values of $\Delta E_{\text {ads }}^{1}$ and $\Delta E_{\text {ads }}^{i}$ are different for different defects and adsorption surfaces. In the first environment of the defect (adsorption centers 3-7) energies $\Delta E_{\text {ads }}^{(i, 1)}$ are generally lower than in the second (adsorption centers 8-15). In the second environment, the excess energies of the endohedral complexes are approximately half the energies of the exohedral complexes, and for a given defect and adsorption surface, they differ from each other by no more than $0.1 \mathrm{eV}$. Fig. 3 shows that the effect of the defect is not limited by the second environment, since the maximum energy of the complexes in the second environment is approximately $0.15 \mathrm{eV}$ lower than for the center with position 0 (on the nanotube wall opposite the defect).

The absolute value of the adsorption energy $\Delta E_{\text {ads }}^{i}$ on center 1 is especially high for the $a$-circ defect for external

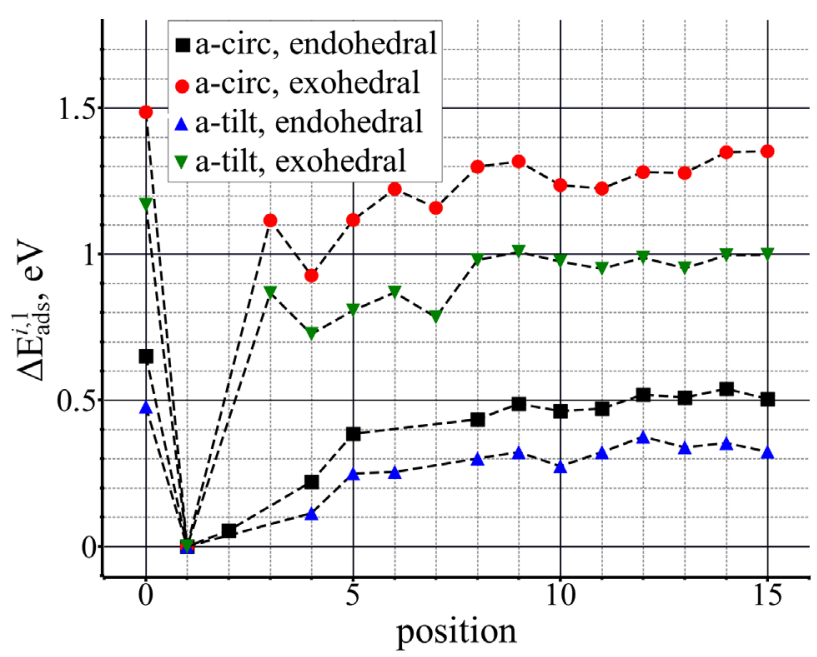

Fig. 3. (Color online) Excess adsorption energy on stable adsorption centers of the inner and outer surfaces of the tube.

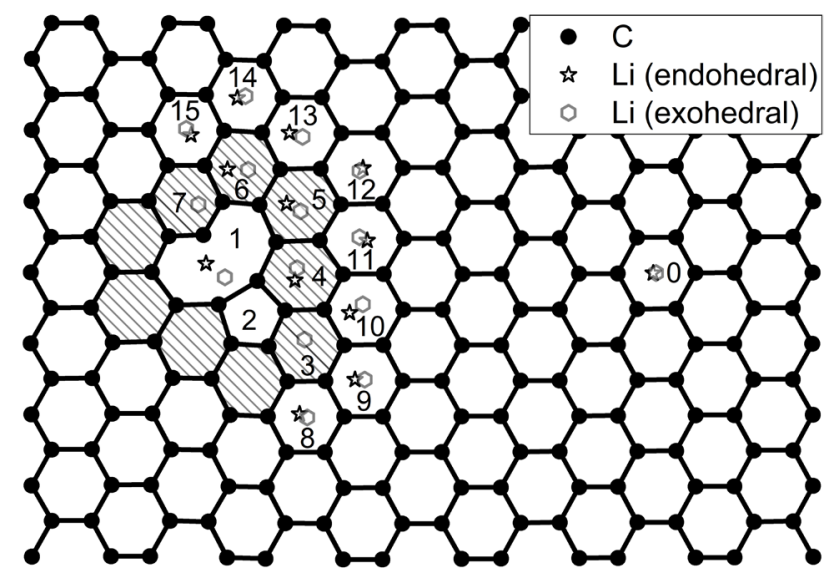

b

Fig. 2. The development of the CNT $(7,7)$ in the vicinity of the defect $a$-circ (a) and $a$-tilt (b). 
adsorption $(3.25 \mathrm{eV})$ and exceeds that for internal adsorption by about $0.7 \mathrm{eV}(2.58 \mathrm{eV})$. For an $a$-tilt defect, the difference between the energies of external $(2.89 \mathrm{eV})$ and internal $(2.39 \mathrm{eV})$ adsorption is smaller $(0.5 \mathrm{eV})$. In position 0 , these values are $1.90,1.73,1.87,1.71 \mathrm{eV}$, respectively. As written above, the adsorption energies for a defect-free tube are 1.81 and $1.66 \mathrm{eV}$ for endohedral and exohedral complexes, respectively. Thus, in position 0 the lithium atom still "senses" the presence of defects of both types, although this manifests in a change in the adsorption energy of less than $0.1 \mathrm{eV}$. On the whole the adsorption centers associated with the considered defects are one and a half to two times more energetically attractive than the centers of a perfect nanotube.

Finally, we note that the above-mentioned correction, which compensates for the superposition error of the basis set, for the considered defect structures during internal adsorption was approximately three times larger than for external ones. Its maximum value for internal adsorption was about $0.35 \mathrm{eV}$. Thus, neglecting this correction can lead to an error of about $20 \%$.

\section{Conclusion}

The results suggest that $a$-circ and $a$-tilt defects on a CNT $(7,7)$ are active centers for the adsorption of $\mathrm{Li}$ atoms, the energetic attractiveness of which is up to twice that for the centers of adsorption on a perfect tube. Taking into account the patterns in the behavior of the adsorption energy of lithium on perfect CNTs, depending on the curvature of their surface, it can be assumed that the indicated ability of defects will persist for tubes of a larger radius, including the case of an infinitely large radius - graphene. The same is less likely to be expected for thinner tubes, where vacancy defects can lead to more radical changes in the atomic and electronic structure of the system.

The energetic attractiveness of adsorption centers on defects is so great that some of the centers of their first environment become unstable: they are unable to keep the lithium atom from moving to the defect. Unstable adsorption centers are more common, even dominant, on the inner surface of the tube and less often on the outer. The ratio of unstable adsorption centers depends on their number and the curvature of the tube surface.

The influence of vacancy defects extends not only to their first environment, it is confidently detected in the second environment, and even at centers opposite the defect. The reason for the long range of the effects of the defect on the activity of lithium adsorption centers is most likely the extreme rigidity of the carbon framework and the subsequent long-range action in the propagation of mechanical stresses and deformations that change the local atomic structure in the vicinity of even distant adsorption centers.

Acknowledgement. This work was financially supported by the Russian Foundation for Basic Research (Grant No. 20-42-740002).

\section{References}

1. P. Sehrawat, C. Julien, S. S. Islam. Mater. Sci. Eng., B. 213, 12 (2016). Crossref

2. D. Di Lecce, P. Andreotti, M. Boni, G. Gasparro, G. Rizzati, J. Y. Hwang, Y. K. Sun, J. Hassoun. ACS Sust. Chem. Eng. 6 (3), 3225 (2018). Crossref

3. X. Zhao, Y. Wu, Y. Wang, H. Wu, Y. Yang, Z. Wang, L. Dai, Y. Shang, A. Cao. Nano Res. 13 (4), 1044 (2020). Crossref

4. L.S. Roselin, R.S. Juang, C.T. Hsieh, S. Sagadevan, A. Umar, R. Selvin, H.H. Hegazy. Mater. 12 (8), 1229 (2019). Crossref

5. F. A. Zubieta-Lopez, J.A. Diaz-Celaya, S. Godavarthi, R. Falconi, E. Chigo-Anota, M. Salazar-Villanueva, F. Ortiz-Chi, M. Acosta-Alejandro. Diam. Relat. Mater. 110, 108108 (2020). $\underline{\text { Crossref }}$

6. J. Noh, J. Tan, D. R. Yadav, P. Wu, K. Y. Xie, C. Yu. Nano Lett. 20 (5), 3681 (2020). $\underline{\text { Crossref }}$

7. S. Sozykin, V. Beskachko. Diam. Relat. Mater. 79, 127 (2017). Crossref

8. S. Sozykin, V. Beskachko, G. Vyatkin. Mater. Sci. Forum. 843, 78 (2016). Crossref

9. J.M. Soler, E. Artacho, J.D. Gale, A. Garc, J. Junquera, P. Ordej, S. Daniel. J. Phys.: Condens. Matter. 14, 2745 (2002). Crossref

10. E. Anikina, A. Banerjee, V. Beskachko, R. Ahuja. ACS Appl. Nano Mater. 2 (5), 3021 (2019). ․ㅏossref

11. S. Sozykin. Comput. Phys. Commun. 262, 107843 (2021). Crossref

12. P. Kostenetskiy, P. Semenikhina. Proc. - 2018 Global Smart Ind. Conf. 2018, 1 (2018). Crossref

13. S. F. Boys, F. Bernardi. Mol. Phys. 100 (1), 65 (2002). Crossref

14. E. Anikina, V. Beskachko. Bull. of the South Ural State Univ., Ser. Matem., Mech., Phys. 12 (1), 55 (2020). (in Russian) [Е. В. Аникина, В.П. Бескачко. Вест. ЮУрГУ. Сер. Матем. Мех. Физ. 12 (1), 55 (2020).]

15. G. Qi, T. Rabczuk. Carbon. 155, 727 (2019). Crossref

16. M. Zhao, Y. Xia, L. Mei. Phys. Rev. B. 71, 165413 (2005). Crossref

17. G. Yang, X. Fan, Z. Liang, Q. Xu, W. Zheng. RSC Adv. 6 (32), 26540 (2016). Crossref

18. M. Khantha, N. Cordero, J. Alonso, M. Cawkwell, L. Girifalco. Phys. Rev. B. 78, 115430 (2008). Crossref

19. W. Koh, J. I. Choi, S. G. Lee, W. R. Lee, S. S. Jang. Carbon. 49 (1), 286 (2010). Crossref

20. B. Song, J. Yang, J. Zhao, H. Fang. Energ. Environ. Sci. 4 (4), 1379 (2011). Crossref

21. Y. Liu, H. Yukawa, M. Morinaga. Comput. Mater. Sci. 30 (1-2), 50 (2004). Crossref

22. J. M. H. Kroes, F. Pietrucci, A. C. T. van Duin, W. Andreoni. J. Chem. Theory Comput. 11 (7), 3393 (2015). Crossref

23. J.E. Padilha, R. G. Amorim, A. R. Rocha, A. J. Da Silva, A. Fazzio. Solid State Commun. 151 (6), 482 (2011). Crossref

24. M. R. C. Hunt, S. J. Clark. Phys. Rev. Lett. 109 (26), 265502 (2012). Crossref 